\title{
Do All Roads Lead to Rome? Exploring the Relationship Between Social Referrals, Referral Propensity and Stickiness to Video-on- Demand Websites
}

\author{
Antonia Köster · Christian Matt • Thomas Hess
}

Received: 19 April 2019/Accepted: 5 June 2020/Published online: 21 July 2020

(C) The Author(s) 2020

\begin{abstract}
Content website providers have two main goals: They seek to attract consumers and to keep them on their websites as long as possible. To reach potential consumers, they can utilize several online channels, such as paid search results or advertisements on social media, all of which usually require a substantial marketing budget. However, with rising user numbers of online communication tools, website providers increasingly integrate social sharing buttons on their websites to encourage existing consumers to facilitate referrals to their social networks. While little is known about this social form of guiding consumers to a content website, the study proposes that the way in which consumers reach a website is related to their stickiness to the website and their propensity to refer content to others. By using a unique clickstream data set of a video-on-demand website, the study compares consumers referred by their social network to those consumers arriving at the website via organic search or social media advertisements in terms of stickiness to the website (e.g., visit length,
\end{abstract}

Accepted after two revisions by Roman Beck.

A. Köster $(\square)$

Chair of Business Informatics, esp. Social Media and Data

Science, University of Potsdam, Karl-Marx-Straße 67,

14482 Potsdam, Germany

e-mail: antonia.koester@uni-potsdam.de

C. Matt

Institute of Information Systems, University of Bern,

Engehaldenstr. 8, 3012 Bern, Switzerland

e-mail: christian.matt@iwi.unibe.ch

\section{T. Hess}

Institute for Information Systems and New Media, Ludwig-

Maximilians-Universität München, Ludwigstr. 28,

80539 Munich, Germany

e-mail: thess@bwl.lmu.de number of page views, video starts) and referral likelihood. The results show that consumers referred through social referrals spend more time on the website, view more pages, and start more videos than consumers who respond to social media advertisements, but less than those coming through organic search. Concerning referral propensity, the results indicate that consumers attracted to a website through social referrals are more likely to refer content to others than those who came through organic search or social media advertisements. The study offers direct insights to managers and recommends an increase in their efforts to promote social referrals on their websites.

Keywords Social referrals · Organic search · Social media advertising - Website stickiness - Referral propensity

\section{Introduction}

The Internet enables users to switch between different content offers within seconds. Content website providers, therefore, strive to design websites that not only attract but also hold consumers' attention (Benlian 2015). In this respect, website stickiness has been recognized as a key factor for profitability (Danaher et al. 2006; Trueman et al. 2000). It captures how long consumers stay on a website and is measured by the average time spent on a website and the average number of page views (Demers and Lev 2001). More time spent on websites indicates a greater interest in the content and can increase advertisement views as well as the likelihood of repeat visits (Bucklin and Sismeiro 2009; Lin et al. 2013).

However, attracting consumers is not a trivial task for content website providers: first, there is a large offer of content on the Internet (often even free of charge), and 
second, there are multiple ways in which consumers can be attracted to websites, which requires providers to find an adequate channel mix through their marketing efforts. To extend reach beyond the consumers who access a website directly by entering a URL, providers predominantly draw attention to their websites through external online channels. These channels include traditional search engines (i.e., paid and organic search results), as well as social media advertisements, which have become a vital tool for companies (Spann et al. 2013). At present, content website providers can profit from social media's success by linking personal communication tools, such as Facebook or WhatsApp, to their websites through social sharing buttons (Schmitt et al. 2011; Koch and Benlian 2015). These buttons can be integrated at little to no cost and are designed to encourage a website's existing customers to provide referrals to their friends (Shi et al. 2013).

So far, little is known about whether this form of "social guidance", i.e., one user attracting another to a website, leads to differential effects on referred consumers' behavior on content websites compared to other online channels. Prior research on channel comparisons does not examine social referrals as an online channel (Bhatnagar et al. 2016; Ghose and Todri-Adamopoulos 2016). Specifically, research has focused predominantly on one channel (Ghose and Yang 2009) or has compared online channels at an aggregated level (Lu et al. 2013; Villanueva et al. 2008; Bar-Gill et al. 2018). However, knowledge of social referrals is essential when marketing budgets are scarce and the sustainability of the business models relies on consumers' attention online.

To fill this gap, we examine the website stickiness of consumers acquired through social referrals and compare it with that of consumers referred through advertisements on social media as well as organic search as a classical form of a user-induced search process. Putting this in a broader context, we contrast different types of sources: interpersonal persuasion attempts by social contacts who have already accessed the content (i.e., a peer-initiated channel), persuasion attempts of content website providers directly approaching consumers through advertisements (i.e., a firm-initiated channel), and proactive consumers accessing the content via search engines (i.e., a consumer-initiated channel). This leads to our first research question: How does website stickiness differ between consumers attracted to a content website through social referrals and consumers referred through social media advertisements or organic search?

Social referrals through social sharing buttons could be valuable for content website providers since consumers attribute higher credibility to information received from other consumers in contrast to advertisements (Godes and Mayzlin 2004). Therefore, social referrals might not only be a cost-effective marketing channel for customer acquisition, but they might also exhibit greater convincing power than other, more traditional channels (Probst et al. 2013). Extant research has either focused on first-stage actors referred directly by the website provider (Koch and Benlian 2015; De Bruyn and Lilien 2008) or on second-stage actors acquired through other consumers (Burtch et al. 2014). However, there is no existing research examining consumers' sharing behavior across different stages of dissemination (Koch and Benlian 2015). In posing our second research question, we seek to provide insights into whether consumers acquired through social referrals are also associated with an increased likelihood to click on social sharing buttons: Are consumers referred through social referrals associated with a higher referral propensity than consumers referred through organic search or social media advertisements?

To address these research questions, a large clickstream data set of a video-on-demand (VOD) website from a major European media company with 956,920 VOD consumers was analyzed. We chose a VOD website, as entertainment content is likely to be forwarded to social contacts (Phelps et al. 2004), and VOD content is a typical experience good, for which consumers are likely to rely on recommendations (Senecal and Nantel 2004).

The findings of this study shed light on social referrals and show that website stickiness to a VOD website and subsequent recommendation behavior is linked to the channel consumers used to arrive at the website. In particular, the findings show that while social referrals score second in terms of website stickiness, consumers acquired through social referrals are associated with the highest referral propensity. Thus, this study contributes to the growing body of literature on channel comparisons (e.g., Bar-Gill et al. 2018; Bhatnagar et al. 2016). More specifically, this study presents evidence for the influence of social referrals compared to consumers' behavior on websites triggered through advertisements or search engine results. Second, while extant literature has investigated sales of tangible goods (Cheung and Thadani 2012) or explored news articles (Bar-Gill et al. 2018), this study analyzes the consumption of VOD content. Third, our research responds to the calls for comparisons of referring channels at the individual level (Lu et al. 2013; Trusov et al. 2009; Bhatnagar et al. 2016). Moreover, as we tracked consumers already acquired through social referrals, this study provides results for website performance measures across different dissemination stages. On the practical side, our study has relevance for VOD website providers, as they may want to understand how social referrals contribute to consumer behavior on their websites. The findings of this study can be used to inform the strategic planning of multiple customer acquisition 


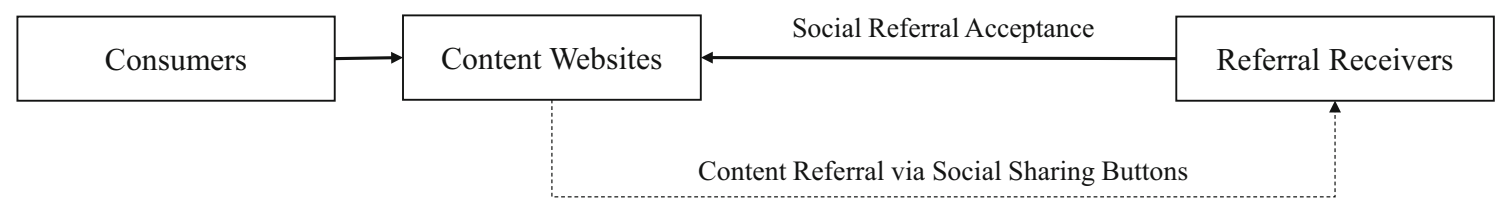

Fig. 1 Social referral process on a content website

Table 1 Online channels

\begin{tabular}{llll}
\hline Online channels & (Advertising) forms & Degree of personalization & Contact origin \\
\hline Search engine results & Paid search results & Personalized & Consumer-initiated \\
Organic search results & & Non-personalized or personalized & Firm-initiated \\
Social media advertisements & Paid posts & Non-personalized & Peer-initiated \\
& Social posts & Personalized & \\
\hline
\end{tabular}

channels and marketing efforts - a pivotal issue for any website that relies substantially on advertising revenues gained through consumers' attention online (Bhatnagar et al. 2016).

\section{Background}

\subsection{Social Referrals as a New Online Channel}

With the prevalence of personal communication tools and social sharing buttons on websites, social referrals are increasingly gaining attention (Lis and Neßler 2013). With these tools, consumers can share information with larger audiences without temporal or geographical constraints, just by accessing a content website and by using the integrated social sharing buttons to refer the offer to their friends (Burtch et al. 2014). Figure 1 illustrates the social referral process. Social referrals have been researched in the broader context of electronic WOM (eWOM), which also comprises seller feedback and product reviews on online platforms, such as forums and online communities (Marchand et al. 2016; Cheung and Thadani 2012; Heimbach et al. 2015). The peculiarity of social referrals in an online context is that they involve communication between individuals with social connections to each other (Lis and Neßler 2013; Shi et al. 2013). Social referrals are perceived as more personal than seller feedback or online consumer reviews, which are generally posted publicly (Shi et al. 2013). Consumers also attribute higher credibility to information received from other consumers than to advertisements (Goh et al. 2013; Trusov et al. 2009).

To ensure conceptual clarity, Table 1 provides a brief overview of the different online channels that are part of our analysis - search, social media advertisement, and social referral - and their main characteristics. Following Anderl et al. (2016), we classify the three online channels according to their degree of personalization and contact origin. The degree of personalization reflects whether messages are individualized based on the targeted persons' characteristics or behaviors. Organic search results are personalized because they are based on individual user queries (Ghose and Yang 2009). Social referrals are personalized because consumers usually share content via personal communication tools with peers who have similar interests. Advertisements on social media can be targeted based on users' prior browsing behavior or their profiles; however, we examine non-personalized advertisements (Verhoef et al. 2010). As a second dimension, online channels can be classified based on their contact origin. Research distinguishes between customer-initiated channels, ${ }^{1}$ in which consumers seek out information themselves, and firm-initiated channels, in which companies initiate marketing communications and push the message to consumers (Li and Kannan 2014; Anderl et al. 2016; Wiesel et al. 2011). In addition to the distinction between customer- and firm-initiated channels, we would like to direct attention to peer-initiated channels, which comprise social referrals. They originate neither from firms nor from interested consumers; they are usually initiated by peers who are already a customer and encourage their peers to consume a certain product or service as well (Burtch et al. 2014).

\footnotetext{
${ }^{1}$ In this study, we use the term consumer-initiated channel.
} 
2.2 On the Effects of Social Referrals and Other Online Channels

Most research has investigated the effectiveness of single online channels, such as searching (Ghose and Yang 2009; Yang and Ghose 2010; Chan et al. 2011), online advertisements (Braun and Moe 2013; De Keyzer et al. 2015), and eWOM (Gu et al. 2012; Cheung and Thadani 2012) on consumer decision making. Only a few studies include more than one online channel in their analysis, examining the interplay of firm-initiated and consumer-initiated channels (e.g., Bhatnagar et al. 2016; Xu et al. 2014; BarGill et al. 2018). Furthermore, previous research has analyzed the effect of eWOM, compared to other online channels, on firm-level outcome variables such as restaurant revenue (Villanueva et al. 2008; Lu et al. 2013). The focus of these studies has been almost exclusively on eWOM in terms of online reviews or other public postings, and less on social referrals transmitted through personal communication tools, where referral recipients and referrers know each other. Considering the conceptual differences between these eWOM types (Marchand et al. 2016), two studies examining social referrals are directly related to our study. In the context of social networking sites, Trusov et al. (2009) compared social referrals transmitted via email with offline marketing activities on new network member registration. Their findings indicate that social referrals have a stronger long-term effect on customer acquisition than traditional advertising. Schmitt et al. (2011) examined the economic value of referred consumers compared with non-referred consumers. However, these two studies do not compare online channels at the individual level, and they only report combined channel effects at an aggregated level. Table 2 underlines the conceptual differences between these studies and our study.

Surprisingly little attention has been paid to estimating the impact of social referrals (i.e., peer-initiated channel) compared to other online channels, such as social media advertisements (i.e., firm-initiated channel) or organic search engine results (i.e., consumer-initiated channel).
The calls by Trusov et al. (2009) and Lu et al. (2013), who argue that more research is needed, particularly with individual-level data, to assess whether consumers attracted in different ways show differential website usage patterns, have not been answered yet. Such research would enable the development of suitable online channel strategies for content websites. We address this research gap with a large data set from a VOD website and present empirical evidence of the differences in individual usage and referral behavior between consumers acquired through social referrals, organic search, and social media advertising.

\section{Research Framework}

Several models for consumers' search and purchase processes have been proposed that illustrate the customer's journey when purchasing products or services (e.g., Rogers 2003; Kotler and Armstrong 2010). These frameworks typically include the following stages: attention, interest, and purchase (De Bruyn and Lilien 2008; Vakratsas and Ambler 1999). Some of these models also include postpurchase behavior, such as loyalty or advocacy behavior (Rogers 2003). In the case of content websites, many providers offer content for free (Lin et al. 2013). These website providers generate their (advertising-related) revenue through consumers' website usage and not through purchasing decisions. Therefore, our conceptual framework in Fig. 2 incorporates attention, activity on the website, and advocacy behavior to account for this context.

As we examine consumers' content consumption and dissemination behavior, our study focuses on website performance behavior. In the attention phase, consumers become aware of the website, develop further interest, and hence, access the website through different channels. Awareness and interest may co-occur in this phase, for instance if consumers become aware of websites through a very persuasive source (e.g., a social tie) (Van den Bulte and Lilien 2001). The literature proposed different ways to

Table 2 Studies on the comparison of social referrals with other channels

\begin{tabular}{|c|c|c|c|c|c|}
\hline Studies & Social referrals & Other channels & Outcome variables & $\begin{array}{l}\text { Analysis } \\
\text { level }\end{array}$ & Data type \\
\hline $\begin{array}{l}\text { Trusov } \\
\text { et al. } \\
\text { (2009) }\end{array}$ & Social referrals via email & Event marketing, media appearances & $\begin{array}{l}\text { Registrations on a } \\
\text { social networking site }\end{array}$ & $\begin{array}{l}\text { Aggregated } \\
\text { effects }\end{array}$ & $\begin{array}{l}\text { User records and } \\
\text { third-party data }\end{array}$ \\
\hline $\begin{array}{l}\text { Schmitt } \\
\text { et al. } \\
(2011)\end{array}$ & $\begin{array}{l}\text { Paid social referrals via } \\
\text { different channels }\end{array}$ & $\begin{array}{l}\text { Other channels (e.g., direct mail, } \\
\text { advertising) }\end{array}$ & $\begin{array}{l}\text { Value of bank } \\
\text { customers }\end{array}$ & $\begin{array}{l}\text { Aggregated } \\
\text { effects }\end{array}$ & $\begin{array}{l}\text { Bank customer } \\
\text { data }\end{array}$ \\
\hline This study & $\begin{array}{l}\text { Social referrals via personal } \\
\text { communication tools }\end{array}$ & $\begin{array}{l}\text { Social media advertisements (i.e., } \\
\text { paid posts), organic search result }\end{array}$ & $\begin{array}{l}\text { Website stickiness and } \\
\text { referral propensity }\end{array}$ & $\begin{array}{l}\text { Individual } \\
\text { effects }\end{array}$ & User records \\
\hline
\end{tabular}




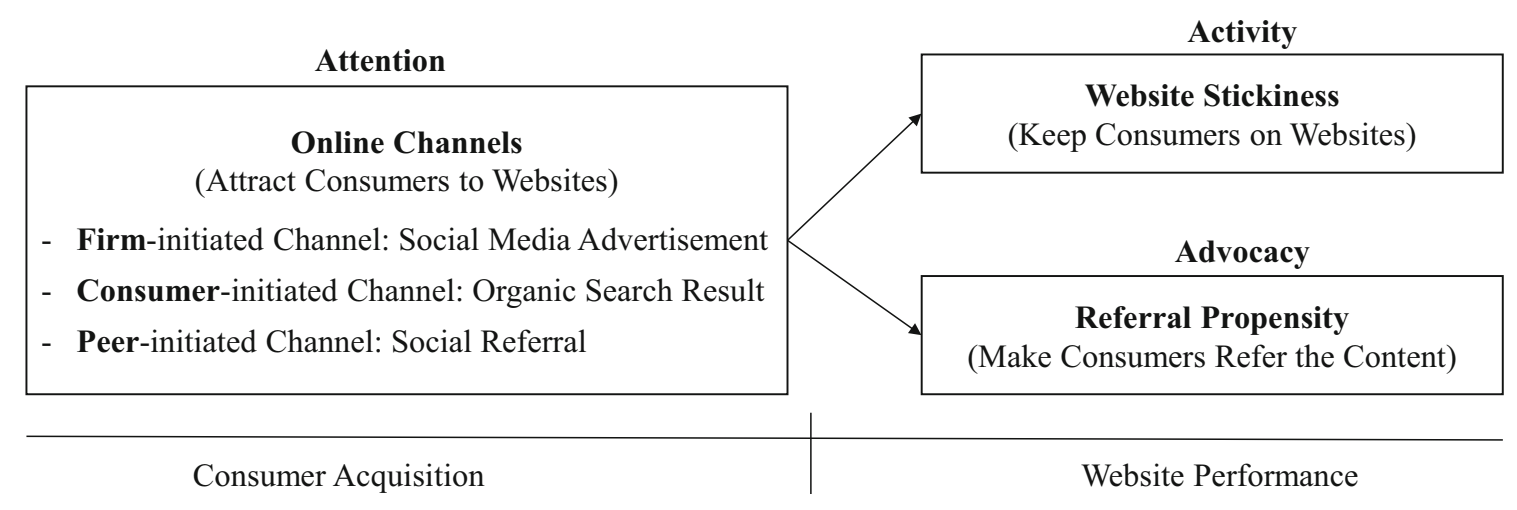

Fig. 2 Website consumer journey

measure website success (Alpar et al. 2001; Demers and Lev 2001; Ghandour et al. 2010). Website performance can be conceptualized as consumers' website usage, financial benefits, or owner satisfaction with the website (Ghandour et al. 2010). In this study, we capture performance in terms of website usage and measure website stickiness (i.e., activity phase) and referral propensity (i.e., advocacy phase), which are both important indicators in explaining the success of content websites.

\subsection{Activity on the Website: Website Stickiness}

Demers and Lev (2001) identified three factors that capture the most relevant dimensions of website performance: website stickiness, reach, and customer loyalty. Website stickiness measures the average time spent on the website per visit and the average number of pages viewed per visit. The reach factor encompasses the extent to which the website attracts unique visitors, and customer loyalty is driven primarily by the average number of visits to the website per unique visitor per period.

Website stickiness has been recognized as a key factor for profitability (Trueman et al. 2000; Danaher et al. 2006). As websites' purposes vary considerably, performance measures must be adjusted (Alpar et al. 2001). E-commerce websites, for example, which focus on direct monetization from selling products, have to balance the desire to keep consumers on their website with the need to encourage them to complete transactions, while media and entertainment websites that rely on advertising revenue may have different goals (Bucklin and Sismeiro 2009). These websites usually strive to increase consumers' attachment to the website and seek to maximize the number of page views in order to increase the number of advertising exposures (Benlian 2015). In fact, Danaher et al. (2006) and Bhatnagar and Ghose (2004) argue that longer visits help to increase advertising revenue and can increase the likelihood of consumers revisiting the website. The number of pages viewed might also increase advertising exposure (Demers and Lev 2001). In this study, we examine a VOD website. These websites usually display advertisements directly before or after a website visitor starts to consume the content. Therefore, this study incorporates the number of videos a specific consumer views as an additional measure of consumers' stickiness to a website.

\subsection{Advocacy of the Website's Content: Referral Propensity}

As noted, reach is an important performance measure for VOD websites. Research in information systems (IS) and marketing has dealt with the outcomes of consumer referral behavior at the firm level and with the drivers of referral behavior at the individual level (De Matos and Rossi 2008; Garnefeld et al. 2013). Different content characteristics have been identified as having an impact on whether people share it. Content that evokes more interest (Berger and Schwartz 2011; Heath et al. 2001), arouses high emotion, or contains more useful information (Berger 2014) is shared more often. Factors such as self-enhancement, identity signaling, extreme satisfaction, and customer commitment have been identified as important motivators for consumer referrals (De Matos and Rossi 2008; Berger 2014). Moreover, consumers' perceptions of information value influence consumers' referral propensity (Pihlström and Brush 2008; Koch and Benlian 2015). Other researchers have claimed that individuals are concerned with whether their actions will impair or enhance their social image and whether this concern will affect their decision to make referrals (Zhang et al. 2014). Social benefits have also been suggested as an important motivator for consumers to share referrals (Hennig-Thurau et al. 2004). The most important reason why consumers engage in referrals may be social capital, defined as "the sum of the actual and potential resources embedded within, available through, and derived from the network of relationships possessed by an individual or social unit" 
(Nahapiet and Ghoshal 1998, p. 243). It governs relations among individuals, making its creation and maintenance relevant (Coleman 1988). Also, social referral incentive systems and standard promotional tactics have been proposed as motives that lead consumers to engage in referrals (Shi et al. 2013; Koch and Benlian 2015).

\section{Hypotheses Development}

\subsection{Website Stickiness}

Several studies have shown that the information gained through informal, interpersonal exchanges makes such recommendations more persuasive and even more influential than traditional marketing efforts (Trusov et al. 2009). Consumers are flooded by traditional forms of advertising, such as e-mail marketing, which decreases the latter's effectiveness (Porter and Golan 2006). Against this backdrop, many companies are increasingly investing in advertising on social media platforms such as Facebook in order to get the attention of potential consumers (Goh et al. 2013; Rishika et al. 2013). In fact, a large amount of traffic to websites can be attributed to social media (Wong 2014). As social referrals are commonly disseminated for personal and non-commercial purposes and only shared with personal connections when a certain threshold of satisfaction is passed, referral recipients will attribute high credibility to this information. They will more likely trust the referred website (Biyalogorsky et al. 2001; Burtch et al. 2014). Supporting this notion, Lin (2007) argues that the more a consumer trusts a website, the more easily the consumer will stick to the website. Principles of triadic balance imply that existing consumers will be more likely to bring in others who they believe would like the company's offer (Schmitt et al. 2011). In addition, social enrichment is the phenomenon that the relationship between the referral receiver and the company is enriched because a family member or friend is a customer of the same firm (Castilla 2005). In short, consumers acquired through social referrals are likely to have a stronger sense of attachment to the website than consumers acquired through social media advertisements. As a result, social referral recipients will be more likely to stick to a website than consumers who received the message directly from the company (Koch and Benlian 2015; Lis and Neßler 2013). Thus, we argue that consumers acquired through social media advertising will terminate their visit earlier and will have a lowered likelihood to view more pages and videos than consumers acquired through social referrals and propose.

Hypothesis 1 Consumers acquired through social referrals are associated with higher website stickiness (measured by visit length, number of page views, and video starts) than consumers acquired through social media advertisements.

However, social referrals might not outperform every other online channel. While consumers acquired through search engines are drawn to the website by clicking on the best possible result according to their search query, consumers acquired through social referrals access a website as a response to a referral from a social contact (Shi et al. 2013). The referrer chooses the content and to a certain extent, also the context of the referral, whereas the recipient only acts on the referral (Burtch et al. 2014). Consumers accessing a website via search engines are actively searching for the content themselves and have relatively more control over the situation. It is therefore reasonable to expect that consumers seeking information might be more inclined to engage with a website than consumers acting on a social referral (Matook et al. 2015). In the context of content websites, this means that consumers who land on a website because of organic search engine results are likely to view more pages and videos to satisfy their information or browsing needs, while social referrals commonly comprise the advocacy of a particular page or video on the website. As a result, this search behavior might also be associated with a comparably longer stay on a website than is the case with consumers acquired through social referrals. Therefore, we hypothesize that consumers accessing a content website via search engines might be more sticky than consumers acquired through social referrals.

Hypothesis 2 Consumers acquired through organic search engine results are associated with higher website stickiness (measured by visit length, number of page views, and video starts) than consumers acquired through social referrals.

\subsection{Referral Propensity}

Consumers' referral propensity reflects their tendency to share information with acquaintances, colleagues, family members, and friends. Individuals are more likely to be influenced by those with whom they share ties, common understandings, and interests (Borgatti and Everett 1992). Prior research has also shown that consumers' fear of being negatively perceived by their social contacts for forwarding messages deters them from doing so (Phelps et al. 2004; Zhang et al. 2014). The fact that a consumer has been referred to the website by another consumer may be interpreted as a signal of social appreciation, which, in turn, positively influences the likelihood of sharing (Pihlström and Brush 2008). Receiving content from others provides social proof or a seal of approval that the content is likely to be good, which should increase the referral propensity (Chen and Berger 2016; van Herpen et al. 2009). Moreover, receiving referrals from social contacts 
rather than from a company is believed to enhance recipients' trust in these messages (Godes and Mayzlin 2004; Villanueva et al. 2008). Therefore, we propose that consumers acquired through social referrals may be associated with an increased likelihood to forward this information to others as social acceptance may be more likely and, owing to higher value perception, the perceived value of the information increases over that of both other channels (Koch and Benlian 2015). Moreover, consumers arriving at the website through search engines or advertisements are primarily driven by self-interest and might be associated with a decreased likelihood to start communicating with their social contacts by sharing a referral. Following this logic, we expect that consumers acquired through social referrals will be linked to a higher referral propensity than consumers acquired through organic search engine results or social media advertisements.

Hypothesis 3 Consumers acquired through social referrals are associated with higher referral propensity than consumers acquired through organic search engine results or social media advertisements.

\section{Research Methodology}

\subsection{Research Setting}

We obtained a clickstream data set from a well-known European media company that provides professional VOD content, such as short video clips, on their website. This VOD website is ideal for our research objective for three reasons: First, the website displays only proprietary, producer-generated videos, which are typical experience goods and one of the most-consumed content forms on the Internet (Godes and Mayzlin 2004; Nelson 1970). Second, the website contains only one form of experience good, since previous research showed differences in consumer behavior (e.g., time per page and number of page views) across product types (Huang et al. 2009). Third, the primary goal of the video content is entertainment, which is likely to be forwarded to others (Phelps et al. 2004).

The studied website has roughly 650,000 visits per day, of which approximately 530,000 are unique consumers. Social sharing buttons are displayed on each page next to the video to make it easier for consumers to share the website with others. The company did not explicitly incentivize social referrals with rewards, which enabled us to examine unsolicited and unrewarded referral decisions (Schmitt et al. 2011). The company tracks outbound social referrals from existing consumers to identify consumers arriving at the website through these social referrals. This recording allowed us to investigate consumer-to-consumer communication, which is typically not made publicly available and is therefore difficult to study (Trusov et al. 2009; Bucklin and Sismeiro 2009).

\subsection{Data Collection}

The goal of this study is to analyze consumers' stickiness to a website and their referral behavior. Therefore, our data set includes only visitors who started to view a video on the website, as we do not seek to understand the factors that drive consumers to respond, for example, to social media advertising or social referrals (Mao and Zhang 2015). We limit the data to consumers from one country, since there might be differences in the presentation of the website's content based on a consumer's country. Furthermore, we analyze unique consumers and do not consider multiple visits in our analysis (Chatterjee et al. 2003). Any time a consumer accesses a URL, website providers record the details of the session with "cookies" on consumers' devices. Among other session-related details, these data points include the online channel from which the consumer arrives, how long the consumer remains on the website (i.e., visit length), how many pages were viewed (i.e., page views), the number of video starts, whether the consumer clicked on the website's social sharing buttons (i.e., referral propensity), the device category, and an identification number. It is important to note that social referral receivers do not know whether the referral was conducted through social sharing buttons or other means, such as copying a URL link.

VOD websites offering free content often only monitor observable, session-related behavior and do not record financial or demographic data, because they do not require consumers to register on their websites (Chatterjee et al. 2003; Burtch et al. 2014). While this prevents consumers' resistance to providing personal data, as well as the effort of having to log in prior to viewing the content, it also restricts website providers' knowledge of their customers. For our study, this poses additional challenges to account for consumer heterogeneity. Following prior literature (Burtch et al. 2014; Bhatnagar et al. 2016), we focus on several critical session-related variables (i.e., location and device) in our estimations to address consumer heterogeneity. Because we analyze consumer data supplied by the media company that is associated with all daily visits, our data does not suffer from the recall problems associated with self-reported data (Huang et al. 2009) and has high external validity.

The data used in this study spans 8 weeks from February 20 to April 20, 2016, and includes all daily visits from the following three online channels: social referral, search engine, and social media advertisements. As bot activity is common on websites and not every bot can be detected by 
the website provider beforehand, we anticipated some bots in our data set as well (Schwarzer et al. 2016). Therefore, we limit the number of page views to 100 and the time spent on the website to a maximum of $5 \mathrm{~h}(18,000 \mathrm{~s}) .882$ observations were deleted due to a higher number of pages viewed, and 242 observations were removed due to higher visit length. However, to better assess the impact of such suspicious activity, we reran the analyses and obtained consistent result patterns. Our final data set comprises 956,920 visits from consumers with a unique identification number and 21 different videos. In general, each video was accessed by consumers referred from all three channels during that time period, and each video in our data set was started more than 1000 times. The average visit contained 1.7 page views lasting a total of $2.28 \mathrm{~min}$.

\subsection{Model Specification}

Based on the hypotheses presented above, we developed three general categories of variables: online channel measures (independent variables), session measures (dependent variables), and control measures.

\subsubsection{Dependent Variables}

The dependent variables in this study are Website Stickiness and Referral Propensity. The use of these performance measures is in line with previous literature (e.g., Moe 2003; Huang et al. 2009; Luo et al. 2013). Our first metric, Website Stickiness, comprises the following measures: page views, visit length, and video starts. Page Views capture the average number of pages viewed on the website for each consumer and measure user engagement in browsing, searching, and interacting with the website (Trueman et al. 2000). Visit Length is defined as the average amount of time that a consumer spends on a given website. It is a function of both the number of page views and the duration of those page views (Bucklin and Sismeiro 2009). The visit length and page views reflect the level of "stickiness" once consumers have accessed the website (Demers and Lev 2001; Danaher et al. 2006). To account for video as the primary media type on the website, we incorporate Video Starts as an additional measure of consumers' stickiness to a website. A high percentage of consumers only viewed one video on the website $($ mean $=1.002$, standard deviation $=0.046)$ and a maximum of five videos. Therefore, we categorized video starts into one video start or more than one video start. Our second metric, Referral Propensity, captures consumers' referral likelihood (Koch and Benlian 2015). Referral Propensity is a binary choice variable that indicates whether a consumer $i$ chose to share the content via social sharing buttons on the website. Referral Propensity takes the value of 1 if the consumer clicked on a sharing button; otherwise, it takes the value of 0 . In general, our data shows that consumers click on the social sharing buttons before and after they start to watch a video.

\subsubsection{Independent Variables}

The independent variable of central interest is the online channel. In this study, we compare consumers referred by social referrals via personal communication tools (e.g., WhatsApp and Facebook), organic search engine results (e.g., Google, Bing, and Yahoo), and social media advertising (e.g., Facebook advertisements). The variable Social Referral indicates whether the consumer was acquired through a social referral from an existing consumer who used a social sharing button (e.g., WhatsApp, Twitter, and Facebook) on the website. The variable Search Engine indicates whether organic search engine results referred the consumer, and the variable Social Media Advertisement indicates whether the consumer was acquired through an online advertisement of the video on Facebook. The media company did not target specific user groups with their Facebook ads (Zhang 2011). The online channels were implemented in the models using dummy coding. The variable Social Media Advertisement therefore equals 1 if the consumer was acquired through advertisements and 0 if not. Accordingly, Search Engine equals 1 if the consumer was acquired through organic search engine results and 0 if not. The remaining $0.1 \%$ of the consumers in our data set were referred through Social Referrals from Facebook, WhatsApp, and Twitter. A rather low rate of consumers acquired through social referrals is fairly typical for content websites (Costello 2015).

\subsubsection{Control Variables}

In addition to the online channels, several other factors could potentially influence consumers' stickiness or referral propensity. Following previous literature, we include a binary indicator, Mobile $($ mobile $=1$, desktop $=0)$, to differentiate mobile device (including tablets) users from desktop users, presuming that a mobile user will be less likely to engage with the website due to the limitations of the smaller interface (Ghose et al. 2012). In the model predicting referral likelihood, we also control for Page Views, since a higher number of page views might indicate a greater interest in the website and highly involved customers tend to give more WOM (Demers and Lev 2001; Dichter 1966; Moe 2003). We use log transforms of the number of page views because its distribution is positively skewed (Wooldridge 2015). In addition, we include Video Starts to control for the number of video views. Posting Duration is another control variable to indicate the number 
Table 3 Description of variables

\begin{tabular}{ll}
\hline Variable & Variable description \\
\hline $\begin{array}{l}\text { Referral } \\
\text { Propensity }\end{array}$ & A binary indicator of whether the consumer used the social sharing buttons on the website during the visit \\
$\begin{array}{l}\text { Page views } \\
\text { Visit length }\end{array}$ & $\begin{array}{l}\text { Dumber of pages viewed } \\
\text { Video starts }\end{array}$ \\
Anline channel & $\begin{array}{l}\text { Acquisition type of the consumer with the categories Social Media Advertisement, Social Referral, and Search Engine. In the } \\
\text { models, the variable was dummy coded with the reference category Social Referral }\end{array}$ \\
Mobile & $\begin{array}{l}\text { A binary indicator of whether the website was accessed via a mobile device or desktop } \\
\text { A binary indicator of whether the video is a general interest video or a specific interest video }\end{array}$ \\
Posting duration & Number of days between the date on which the video had been posted on the website and the date of the visit
\end{tabular}

Table 4 Descriptive statistics of independent variables

\begin{tabular}{lccccr}
\hline Variable & Units & Mean & SD & Min. & Max. \\
\hline Social media advertisement & $0-1$ & 0.952 & 0.214 & 0.00 & 1.00 \\
Search engine & $0-1$ & 0.047 & 0.212 & 0.00 & 1.00 \\
Social referral & $0-1$ & 0.001 & 0.032 & 0.00 & 1.00 \\
Mobile & $0-1$ & 0.936 & 0.245 & 0.00 & 1.00 \\
Video type* & $0-1$ & 0.281 & 0.450 & 0.00 & 1.00 \\
Posting duration* & Days & 10.322 & 8.168 & 1.00 & 68.00 \\
\hline
\end{tabular}

Sample size $=956,920 ; *$ Sect. 6.3: Sample size $=955,311$

of days between the date on which the video had been posted on the website and the date of the visit. We also include a proxy for the level of usefulness of the video, as we expect general interest videos to appeal to a larger audience. Video Type is measured as a binary variable, with a value of 0 for videos covering general interest topics and 1 for videos with a specific topic focus. Table 3 describes the variables used in this study.

Table 4 presents the descriptive statistics for the channels and control variables. Table 5 provides the descriptive statistics for the dependent variables by referral channel and for the full sample.

The software Stata/IC 12.1 was used for the analysis. Each model was tested for multicollinearity among the independent variables. The maximum variance inflation factors are below 2.00, which indicates that there is no multicollinearity.

To evaluate Hypotheses 1 and 2, we estimated separate models to analyze the effects of online channels on website stickiness. We applied OLS regression for the variable Visit Length, negative binomial regression for the variable Page Views, and logistic regression for the variable Video Starts. In the equations, consumers are indexed by $i$. We partitioned the online channels into three categories: advertisement, search engine, and social referral. Each consumer falls into only one category. The variable Social Media Advertisement therefore equals 1 if the consumer was acquired through an online advertisement on Facebook and 0 if otherwise. Accordingly, Search Engine equals 1 if the consumer was acquired through organic search engine results and 0 if otherwise. The reference group comprises Social Referrals. For example, the coefficient on Social Media Advertisement will state the average difference between the visit length of consumers acquired via social media advertisements and those via social referrals, holding constant the other variables in the regression.

To estimate the effect of social referrals in comparison to the other two channels regarding visit length, we used an OLS regression model. We log transformed Visit Length because the distribution is positively skewed (Wooldridge 2015). The regression model is as follows:

$$
\begin{aligned}
\operatorname{Ln}\left(\text { Visit Length }_{i}\right)= & \alpha+\beta_{1} \text { Social Media Advertisement }_{i} \\
& +\beta_{2} \text { Search Engine }_{i}+\beta_{3} \text { Mobile }_{i}+\varepsilon_{i}
\end{aligned}
$$

The variable Page Views represents count data and its variance is larger than its mean. Therefore, we applied the negative binomial regression model on the assumption that Page Views follow the negative binomial distribution. Negative binomial regression relies on a log transformation of the conditional expectation of the dependent variable (i.e., Page Views) and requires an exponential transformation of the estimated coefficients to assess and interpret the effects. The resulting regression model is as follows:

$$
\begin{aligned}
\left.\operatorname{Ln}\left(\text { E }\left._{\text {Page Views }}\right|^{*}\right)\right)= & \alpha+\beta_{1} \text { SocialMediaAdvertisement }_{i} \\
& +\beta_{2} \text { SearchEngine }_{i}+\beta_{3} \text { Mobile }_{i}
\end{aligned}
$$

where $E\left(\right.$ Page Views $\left.\left.\right|^{*}\right)$ is the expectation of page views conditional on the set of the explanatory variables on the right-hand side of the equation. 
Table 5 Descriptive statistics of dependent variables

Visit length (s), page views (positive integer), video starts $(0-1)$, referral propensity $(0-1)$

\begin{tabular}{lllll}
\hline & Social Referral & Search Engine & Social Media Advertisement & Full Sample \\
\hline$N$ & 979 & 45,072 & 910,869 & 956,920 \\
Visit length & & & & \\
Min & 3 & 1 & 1 & 1 \\
Max & 7424 & 17,993 & 14,647 & 17,993 \\
Mean & 181.899 & 1681.962 & 60.576 & 137.069 \\
SD & 559.512 & 2752.334 & 156.096 & 705.904 \\
Page views & & & & 1 \\
Min & 1 & 1 & 1 & 100 \\
Max & 50 & 100 & 100 & 1.692 \\
Mean & 1.581 & 9.133 & 1.324 & 4.906 \\
SD & 2.272 & 13.558 & 3.648 & 0.002 \\
Video starts & & & & 0.046 \\
Mean & 0.005 & 0.031 & 0.000 & \\
SD & 0.071 & 0.175 & 0.014 & 0.002 \\
Referral propensity & & & 0.042 \\
Mean & 0.005 & 0.002 & 0.002 & \\
SD & 0.071 & 0.039 & & \\
\hline
\end{tabular}

To estimate the effects on Video Starts, we used logistic regression since we defined video starts as a dichotomous dependent variable (Wooldridge 2015).

$$
\begin{aligned}
\operatorname{Logit}_{\left(\text {Video Starts }_{i}\right)=} & \alpha+\beta_{1} \text { Social Media Advertisement }_{i} \\
& +\beta_{2} \text { Search Engine }_{i}+\beta_{3} \text { Mobile }_{i}
\end{aligned}
$$

For Hypothesis 3, logistic regression was chosen to analyze the effect of online channels on referral propensity. The specification of the model for testing Hypothesis 3 is:

$$
\begin{aligned}
& \text { Logit }_{\left(\text {Referral Propensity }_{i}\right)} \\
& \begin{aligned}
= & +\beta_{1} \text { Social Media Advertisement }_{i} \\
& +\beta_{2} \text { Search Engine }_{i}+\beta_{3} \text { Mobile }_{i} \\
& +\beta_{4} \ln \left(\text { Page Views }_{i}\right)+\beta_{5}\left(\text { Video Starts }_{i}\right)
\end{aligned}
\end{aligned}
$$

In Eq. (4), consumers are indexed by $i$. The effect of Social Media Advertisement in comparison with Social Referral is reflected in $\beta_{1}$, and the effect of Search Engine in comparison with Social Referral is reflected in $\beta_{2}$. For example, a positive coefficient $\beta_{1}$ will provide evidence that consumers acquired through advertisements have a higher propensity to make a referral via social sharing buttons than do the consumers already referred by social referrals.

\section{Results}

\subsection{Website Stickiness}

We present the regression results for Visit Length and Page Views in Table 6. The results for Video Starts are displayed in Table 7. Model 1 presents the results of the control-only model and Model 2 presents the full model. For page views and video starts, we report Nagelkerke's pseudo $R^{2}$ value (Nagelkerke 1991), acknowledging that low pseudo $R^{2}$ statistics in logistic regression are the norm (Hemmert et al. 2018; Hosmer et al. 2013).

The first two columns provide the results for visit length. In accordance with Hypotheses 1 and 2, we find that consumers acquired through social referrals spend on average approximately $\operatorname{Exp}(0.453)=1.57$ times more time on the website than consumers acquired through social media advertisements and approximately $\operatorname{Exp}(-1.990)=0.14$ times less time than consumers acquired through organic search engine results. The third and fourth column present the results with regard to the breadth of the visit. Model 1 presents the control-only model. The expected number of page views is approximately $\operatorname{Exp}(0.114)=1.12$ times higher for consumers acquired through social referrals than for those acquired through social media advertisements. As hypothesized, we observe that consumers referred from organic search engine results are associated with viewing more pages. Search results compared with social referrals are expected to have a rate $\operatorname{Exp}(1.621)=5.06$ times greater for page views.

We also measured time per page (i.e., the average number of seconds spent per page) with similar results. Consumers acquired through search engines have a significantly higher time per page than consumers acquired through social referrals, and these consumers have a significantly higher time per page than consumers acquired through social media advertisements. 
Table 6 Regression analysis results: visit length and page views

$* p<0.05 ; * * p<0.01 ; p$ values are reported in parentheses

Table 7 Regression analysis results: video starts
$C B$ choice-based sample $* p<0.05 ; * * p<0.01 ; p$ values are reported in parentheses

\begin{tabular}{|c|c|c|c|c|}
\hline \multirow[t]{2}{*}{ Independent variables } & \multicolumn{2}{|c|}{ Dependent variable: visit length } & \multicolumn{2}{|c|}{ Dependent variable: page views } \\
\hline & $\begin{array}{l}\text { Model } 1 \\
\text { Estimate }\end{array}$ & $\begin{array}{l}\text { Model } 2 \\
\text { Estimate }\end{array}$ & $\begin{array}{l}\text { Model } 1 \\
\text { Estimate }\end{array}$ & $\begin{array}{l}\text { Model } 2 \\
\text { Estimate }\end{array}$ \\
\hline Intercept & $\begin{array}{l}4.943 * * \\
(0.000)\end{array}$ & $\begin{array}{l}4.349 * * \\
(0.000)\end{array}$ & $\begin{array}{l}1.717 * * \\
(0.000)\end{array}$ & $\begin{array}{l}0.707 * * \\
(0.000)\end{array}$ \\
\hline Social media advertisement & & $\begin{array}{l}-0.453^{* *} \\
(0.000)\end{array}$ & & $\begin{array}{l}-0.114 * * \\
(0.000)\end{array}$ \\
\hline Search engine & & $\begin{array}{l}1.990 * * \\
(0.000)\end{array}$ & & $\begin{array}{l}1.621 * * \\
(0.000)\end{array}$ \\
\hline Mobile & $\begin{array}{l}-1.317^{* *} \\
(0.000)\end{array}$ & $\begin{array}{l}-0.322^{* *} \\
(0.000)\end{array}$ & $\begin{array}{l}-1.362 * * \\
(0.000)\end{array}$ & $\begin{array}{l}-0.327^{* *} \\
(0.000)\end{array}$ \\
\hline Prob $>F$ & 0.000 & 0.000 & & \\
\hline Prob $>$ Chi squared & & & 0.000 & 0.000 \\
\hline Log likelihood & & & $-1,590,198.3$ & $-1,503,236.3$ \\
\hline$R^{2}$ & 0.092 & 0.278 & & \\
\hline (Pseudo) $R^{2}$ & & & 0.159 & 0.304 \\
\hline Sample size & 956,920 & 956,920 & 956,920 & 956,920 \\
\hline
\end{tabular}

\begin{tabular}{|c|c|c|c|c|c|}
\hline & & $\begin{array}{l}\text { Model } 1 \\
\text { Estimate }\end{array}$ & $\begin{array}{l}\text { Model } 2 \\
\text { Estimate }\end{array}$ & $\begin{array}{l}\text { Model } 1(\mathrm{CB}) \\
\text { Estimate }\end{array}$ & $\begin{array}{l}\text { Model } 2(\mathrm{CB}) \\
\text { Estimate }\end{array}$ \\
\hline & Intercept & $\begin{array}{l}-3.967 * * \\
(0.000)\end{array}$ & $\begin{array}{l}-4.550^{* *} \\
(0.000)\end{array}$ & $\begin{array}{l}-0.0596 \\
(0.149)\end{array}$ & $\begin{array}{l}-0.462 \\
(0.375)\end{array}$ \\
\hline & Intercept (revised) & & & -3.972 & -4.374 \\
\hline & Social media advertisement & & $\begin{array}{l}-3.006^{* *} \\
(0.000)\end{array}$ & & $\begin{array}{l}-3.079 * * \\
(0.000)\end{array}$ \\
\hline & Search engine & & $\begin{array}{l}1.437 * * \\
(0.001)\end{array}$ & & $\begin{array}{l}1.238^{*} \\
(0.017)\end{array}$ \\
\hline & Mobile & $\begin{array}{l}-3.585^{* *} \\
(0.000)\end{array}$ & $\begin{array}{l}-1.011^{* *} \\
(0.000)\end{array}$ & $\begin{array}{l}-3.580^{* *} \\
(0.000)\end{array}$ & $\begin{array}{l}-1.120^{* *} \\
(0.000)\end{array}$ \\
\hline & Prob $>$ Chi squared & 0.000 & 0.000 & 0.000 & 0.000 \\
\hline & Log likelihood & -9688.1004 & -7946.9864 & -3813.2482 & -2547.9392 \\
\hline$C B$ choice-based sample & (Pseudo) $R^{2}$ & 0.187 & 0.334 & 0.387 & 0.616 \\
\hline $\begin{array}{l}* p<0.05 ; * * p<0.01 ; p \text { values } \\
\text { are reported in parentheses }\end{array}$ & Sample size & 956,920 & 956,920 & 20,716 & 20,716 \\
\hline
\end{tabular}

Column one and two show the results for video starts for the total sample and column three and four the results for a smaller sample size (see Sect. 6.3).

Confirming Hypothesis 1, consumers acquired through social referrals are associated with starting significantly more videos than consumers arriving at the website via social media advertisements. The odds of viewing more than one video on the website are approximately $\operatorname{Exp}(3.006)=20.21$ times greater for social referrals than for social media advertisements. In accordance with Hypothesis 2, consumers acquired through search engines are associated with an increased likelihood to start more than one video, compared with consumers arriving at the website via social referrals. The odds of viewing more than one video on the website are approximately $\operatorname{Exp}(1.437)=$ 4.21 times greater for search results than for social referrals.

\subsection{Referral Propensity}

Next, we present the results for Referral Propensity in Table 8 , along with model fit statistics. For each variable, the logistic regression estimates the effect of the variable on the referral propensity, given that all other covariates remain constant. The likelihood ratio test assesses the overall fit of the model. The analysis of each model 
Table 8 Regression analysis results: referral propensity
$C B$ choice-based sample

${ }^{*} p<0.05 ; * * p<0.01 ; p$ values are reported in parentheses

\begin{tabular}{lllll}
\hline Independent variables & \multicolumn{2}{l}{ Dependent variable: referral propensity } \\
\cline { 2 - 5 } & $\begin{array}{l}\text { Model 1 } \\
\text { Estimate }\end{array}$ & $\begin{array}{l}\text { Model 2 } \\
\text { Estimate }\end{array}$ & $\begin{array}{l}\text { Model 1 (CB) } \\
\text { Estimate }\end{array}$ & $\begin{array}{l}\text { Model 2 (CB) } \\
\text { Estimate }\end{array}$ \\
\hline Intercept & $-8.567^{* *}$ & $-7.290^{* *}$ & $-4.743^{* *}$ & $-3.263^{* *}$ \\
& $(0.000)$ & $(0.000)$ & $(0.000)$ & $(0.000)$ \\
Intercept (revised) & & & -8.658 & -7.178 \\
Social media advertisement & & $-1.137^{*}$ & & $-1.254^{*}$ \\
& & $(0.011)$ & & $(0.016)$ \\
Search engine & & $-1.472^{* *}$ & & $-1.914^{* *}$ \\
& & $(0.002)$ & & $(0.000)$ \\
Mobile & $2.214^{* *}$ & $2.074^{* *}$ & $2.286^{* *}$ & $2.061^{* *}$ \\
Page views & $(0.000)$ & $(0.000)$ & $(0.000)$ & $(0.000)$ \\
& $0.492^{* *}$ & $0.525^{* *}$ & $0.585^{* *}$ & $0.684^{* *}$ \\
Video starts & $(0.000)$ & $(0.000)$ & $(0.000)$ & $(0.000)$ \\
& 0.385 & 0.549 & 0.257 & 0.563 \\
Prob $>$ Chi squared & $(0.448)$ & $(0.284)$ & $(0.652)$ & $(0.326)$ \\
Log likelihood & 0.000 & 0.000 & 0.000 & 0.000 \\
(Pseudo) $R^{2}$ & $-12,366.104$ & $-12,360.855$ & -5764.7014 & -5753.3499 \\
Sample size & 0.011 & 0.012 & 0.030 & 0.033 \\
\hline & 956,920 & 956,920 & 20,797 & 20,797 \\
\hline
\end{tabular}

indicates a good model fit with a highly significant likelihood ratio $(p=0.000)$. In column three and four, we present the results with a smaller sample size for robustness (see Sect. 6.3).

Using the results in the second column of Table 8, the odds ratio of the variable Social Media Advertisement equals $0.321(\operatorname{Exp}(-1.137))$. The odds of a referral are approximately $\operatorname{Exp}(1.137)=3.12$ times greater for consumers accessing the website through social referrals than for consumers landing on the website via social media advertisements, supporting Hypothesis 3. The odds ratio of the variable Search Engine equals $0.229(\operatorname{Exp}(-1.472))$. The odds of a referral are approximately $\operatorname{Exp}(1.472)=$ 4.36 times greater for consumers accessing the website through social referrals than for consumers landing on the website via organic search engine results, which also supports Hypothesis 3. Video starts do not have a significant influence on consumers' referral propensity, whereas the influence of the device and number of page views is significant.

\subsection{Robustness Checks}

Since our goal is to estimate the impact of the online channels on consumers' stickiness to the website and their referral propensity, we performed a series of robustness tests. First, we repeated the analyses using a model that controls for the different videos in our data set. By adding a dummy for each of the 21 videos (Video) in our model, we absorbed the effects particular to each video. In addition, we included Posting Duration as another control variable to indicate the number of days between the date on which the video had been posted on the website and the date of the visit (Burtch et al. 2014). Since the Posting Duration variable is measured in days and includes zero, we increased the posting duration by one, which allowed us to use the logarithm. To measure visit length and page views while controlling for video effects and posting duration, we limited the data set and excluded all consumers viewing more than one video during their visit. Therefore, the models do not include the number of video starts. The results continue to support the hypotheses tests. The variable Social Media Advertisement is still significantly negatively related to visit length and page views, and Search Engine is positively related to both outcome variables compared with the Social Referral variable. Posting Duration has a negative and significant influence. To estimate referral propensity, we also limited the data to the first video view in order to control for posting duration and the video. Therefore, referral propensity refers to the first video that was viewed on the website. Accordingly, referral propensity captures whether a consumer clicked on a sharing button before or after the first video was viewed. Additionally, we considered the Video Type of the first video viewed, to account for the difference of specific interest videos versus general interest videos. We find that general interest videos have a significantly higher referral propensity than special interest videos. Posting Duration has a positive and significant influence on referral propensity. The variables Search Engine and Social Media 
Advertisement are still significantly negatively related to consumers' referral propensity compared with the Social Referral variable. The results of the effects of the channels on referral propensity remain stable, supporting the theoretical argument that the channel, i.e., social influence, is associated with the propensity to share the videos.

Second, the occurrence of 1's in our dependent variables Video Starts and Referral Propensity can be considered a rare event. The percentage of consumers viewing more than one video and the percentage of consumers using social sharing buttons is low in our data set. The majority of consumers only view one video $(N=955,311)$ or do not use the share button $(N=955,213)$. Therefore, our dependent variables Video Starts and Referral Propensity are not balanced. The biases that rare events create in estimating logit models have been discussed in the literature (King and Zeng 2001; Ben-Akiva and Lerman 1985). To overcome the problem of misclassification, we re-estimate the model while deliberately under-sampling the nonsharing consumers so that a more balanced sample of ones and zeros in the dependent variable is obtained. This sampling technique is called choice-based sampling (King and Zeng 2001). Because this method does not yield consistent estimates of the intercept when traditional maximum likelihood methods are used, we adjust the estimated intercepts for each alternative. Manski and Lerman (1977) developed a weighted endogenous sampling maximum likelihood estimator, which accounts for the different weights in the zeros and ones from the population. However, this estimator has the undesirable property of increasing the standard errors of the estimates (Greene 2003). Therefore, we adjust the estimated intercepts for each alternative by subtracting $\ln \left(S_{i} / P_{i}\right)$ from the exogenous maximum likelihood estimates of the intercept, where $S_{i}$ is the percentage of observations for alternative $\mathrm{i}$ in the sample, and $P_{i}$ is the percentage of observations for alternative $i$ in the population (Ben-Akiva and Lerman 1985).

For Video Starts, we estimated the model in Table 7 again with a choice-based sample that balances the number of consumers viewing one video and consumers viewing several videos on the website. Our smaller data set comprises 1609 consumers who decided to view more than one video and 19,107 randomly sampled consumers (2\% of the sample if Video Starts $=0$ ) who did not view more than one video during their visit. The estimates are reported in the third and fourth column of Table 7 . We find that the logistic regression with rare event correction produces estimates very similar to those generated by the full sample, which further improves our confidence in the finding that social referrals are positively associated with video starts compared to social media advertisements, but not with organic search.
For Referral Propensity, we estimated the models again with a choice-based sample that balances the number of sharing and non-sharing consumers. Our smaller data set to test Hypothesis 3 comprises 1707 consumers who decided to click on social sharing buttons and 19,090 randomly sampled consumers $(2 \%$ of the sample if Referral Propensity $=0$ ) who did not click on the sharing buttons during their visit. The estimates are reported in the third and fourth column of Table 8. To summarize, having examined the relationship between social referrals, website stickiness and referral propensity via different model specifications and data sizes, we find consistent evidence for our results.

\section{Discussion}

We investigated how consumers' stickiness changes together with the online channel, and how sharing behavior is related to channels as well. We observed how social referrals, in comparison with referrals from organic search engine results and social media advertisements, translate into website stickiness and how this affects the likelihood of consumers referring videos to others. Moreover, our unique data set allowed us to observe the actual website usage of both first-stage actors (e.g., consumers acquired through social media advertisements) and second-stage actors (e.g., consumers already acquired through social referrals). Therefore, we were able to examine referral propensity across different stages of dissemination. Our results suggest that consumers who find video content through organic search engine results visit more pages, spend more time on a website, and have more video starts than consumers acquired through social referrals. One reason could be that consumers who proactively searched for content have a strong content preference match (Lucas et al. 2001) and are inclined to spend more time on a website and explore the website further than consumers accessing the website as a response to a message referring to one specific video that was sent to them by their social contacts. In line with previous research in other contexts (e.g., Trusov et al. 2009; Villanueva et al. 2008), consumers acquired through social contacts have a positive effect on firm-level outcome variables compared with marketer-induced consumers. Specifically, referrals from social contacts persuade consumers to stay on the website longer, and these consumers are more inclined to explore more pages and also view more videos than consumers acquired through social media advertisements. This finding is especially interesting since we examined consumers drawn to the website through advertisements that are displayed on a social networking site (e.g., Facebook). From the viewpoint of consumers, social networking sites are 
primarily used for interpersonal communication, blurring the lines between consumer- and marketer-initiated content (De Keyzer et al. 2015; Matook et al. 2015). Although social media advertisements are displayed in a social and personal environment, we still observe significant differences in consumers' stickiness on the website.

Referrals by first-stage actors are essential because the ability to reach second-stage actors is based on the firststage actors' referral decisions (De Bruyn and Lilien 2008). Although these referral decisions are important, an ongoing viral effect is only possible if second-stage actors also share the information with their social network. In general, our data set shows that consumers arrive at the website less frequently via social referrals than through organic search engine results or social media advertisements. Although the overall share of consumers arriving through social referrals at the analyzed website is comparably low, we provide evidence that consumers already acquired through social referrals (i.e., second-stage actors) are more likely to initiate referrals than consumers acquired through social media advertisements or search engines. The literature indicates that consumers are likely to attribute great importance to signals that indicate the popularity and value of the content (Koch and Benlian 2015). The fact that second-stage actors access the content through a social referral may be perceived as a signal of social acceptance, which is linked with a higher referral propensity. This finding shows that it is important to consider not only the reach of online channels but also the actual behavior of converted consumers on the website. Social referrals as an acquisition channel should not be underestimated, as consumers acquired through social referrals are associated with a higher likelihood of referring a consumer, than consumers acquired through social media advertisements or organic search engine results, which may trigger a viral loop.

\subsection{Implications for Research and Practice}

Our study contributes to eWOM literature at the crosssection of IS and marketing by expanding our understanding of the antecedents of website stickiness in general and online social referral behavior in particular. First, prior literature on eWOM has focused on examining the impact of online reviews on consumer behavior or firm performance (e.g., Chen and Xie 2007; Chevalier and Mayzlin 2006; Cheung and Thadani 2012), and there has been little emphasis on exploring the effectiveness of social referrals via personal communication tools on consumer behavior (Shi et al. 2013; Köster et al. 2015). We extend previous research by examining how social referrals are related to consumers' behavior on a VOD website. Second, we provide results for a website only offering intangible goods (i.e., videos), whereas most academic literature has investigated the effect of interpersonal persuasion on consumer decision making of tangible goods, such as book sales (e.g., Chevalier and Mayzlin 2006; Li and Hitt 2008; Chen et al. 2004). Therefore, our research differs from extant approaches since it measures profitability in terms of consumers' website usage and not in terms of product or service sales (Cheung and Thadani 2012). Third, this study contributes to the literature on information processing. While prior research has identified website design variables, such as personalization cues (Benlian 2015), perceived social presence (Cyr et al. 2009), and the emotional states of the consumer (Mahnke et al. 2015), as factors that influence consumers' behavior, our results suggest that how consumers are drawn to the website may also be linked to how they consume and share content. Fourth, we compare online channels at the individual level, unlike prior research, which has focused on aggregated data (e.g., Lu et al. 2013; Villanueva et al. 2008). Essentially, this research responds to the calls from Lu et al. (2013), Trusov et al. (2009), and Bhatnagar et al. (2016), who have stressed the need to compare online channels at the individual level. Lastly, our data set incorporates consumers already acquired through social referrals, which allows us to compare the referral propensity across different stages of dissemination, whereas extant research (e.g., Burtch et al. 2014; De Bruyn and Lilien 2008; Koch and Benlian 2015) has focused on either first-stage (i.e., consumers acquired through firm-initiated channels) or second-stage (i.e., consumers acquired through costumer-initiated channels) actors.

Our research has direct implications for the management of different online channels. Owing to a plurality of content offers on the Internet, one of the primary objectives and challenges for VOD website providers is to attract more consumers and to keep them on their websites as long as possible. While there are multiple online channels that can draw consumers to a website, providers seek to understand whether specific online channels perform better than others in achieving their goals. We have placed a particular focus on social referrals as a rather new and inexpensive means for VOD website providers to utilize their consumers to attract their friends by using a social sharing button. In particular, consumers acquired through organic search results have a higher stickiness to a website than consumers arriving at the website through social referrals. Therefore, VOD website providers should continue investing in SEO to make consumers aware of their content. In addition, they should facilitate social referrals, since consumers acquired via social referrals exhibit higher visit lengths and breadths than consumers acquired through social media advertisements. This is especially worth noting considering every consumer arriving at the website via social media 
advertisements causes acquisition costs, whereas sharing buttons provide a rather cost-effective mechanism to attract potential consumers to the website (Shi et al. 2013). Furthermore, VOD website providers could make inferences from the observed behavior of the referrers about the video content preferences of referral receivers. As a result, the website provider is able to serve the referred customer in a tailored way, something that takes time to learn for other newly acquired customers. Because of this informational advantage, the provider might be able to generate higher revenues from referred customers at the beginning of the relationship.

A consumer's decision to share the video on the website is an important measure for companies to investigate because such an act of sharing attracts potential consumers to the website. These consumers, owing to the way they have been drawn to the website, exhibit higher referral propensity. This study shows that consumers acquired through social referrals are more likely to start influencing their friends than consumers who arrived at the website through other channels (i.e., social media advertisements or search engines). Therefore, VOD website providers should not underestimate social referrals and can utilize our findings to design social referral incentive schemes to facilitate these types of referrals (Shi et al. 2013). Existing studies provided guidance about the design and utilization of rewards in other contexts (Biyalogorsky et al. 2001; Köster et al. 2015) and have quantified the influence of reward allocation schemes and tie strength on referral propensity (Ryu and Feick 2007; Shi et al. 2013). Referral rewards do not have to be monetary; they can also be symbolic (Verlegh et al. 2013). VOD website providers could facilitate the referral engagement of consumers by investing in such a social referral incentive system or by promoting the usage of their social sharing buttons (Shi et al. 2013). Consumers can hardly distinguish between advertisements and friends' recommendations, as social referrals might be incentivized by website providers (e.g., affiliate links, referral reward programs). Marketing managers could foster social referrals, for instance, by integrating multiple sharing buttons, by placing them at prominent places on their websites, and by using sharing buttons that move with the content. Finally, they might integrate statements such as "send this to a friend" at the end of a video clip. Thus, besides financially pushing social referrals, managers also have other options for promoting social referrals since they have full control over their websites in contrast to search engines or social media platforms.

\subsection{Limitations and Further Research}

Our research has several limitations that might be addressed by further research. First, we mainly focused on the effects of the online channel on website visitors' behavior. Additional studies could concentrate on the specific effects induced by different videos for different users and tie those effects to distinct website outcomes. Second, we derived our data from a leading VOD website providing short video clips. Although this is a common type of VOD video platform in the European media market, other types of video platforms might possess different characteristics and our results might therefore not be directly transferable. Future studies could sample different content types (e.g., user-generated videos, podcasts) to test whether the results remain consistent in other domains (Oestreicher-Singer and Zalmanson 2013; Bar-Gill et al. 2018). Third, our study is based on a large set of observational data that allows for a comparably objective measurement of user behavior. Although clickstream data represents an important source of behavioral insights, the data we analyzed in this study limited our modeling effort in a number of ways. Owing to missing detailed sociodemographic information on the users, the results have to be interpreted cautiously. While we found evidence that social referrals are associated with website stickiness and referral propensity, future studies could test whether there exists a selection effect of users being more prone to social referrals, spending more time on websites or having higher sharing dispositions. Although Danaher et al. (2006) found that variability in visit duration is driven mostly by the situation and only to a small degree by individual traits, further research could analyze data collected on websites with mandatory registration, in order to address consumer heterogeneity (Özpolat et al. 2013). Future research could also apply longitudinal or experimental methods that allow to detect direct causal inferences of the reported relationships. Fourth, our data was based on last-click metrics which ignore prior channel touches and, therefore, might give biased estimates on the credits of each channel (Kannan et al. 2016). However, data sets that observe consumers over time and across multiple channels often provide new challenges concerning data reliability (Chatterjee et al. 2003; Anderl et al. 2016). Furthermore, consumers of hedonic, low-involvement products, such as the free online videos in our study, usually do not engage in elaborate information processing and browsing behavior prior to the focal website visit, which confirms the suitability of lastclick metrics (Huang et al. 2009; Wiesel et al. 2011; Vakratsas and Ambler 1999). Fifth, although cookies recognize subsequent visits, we have excluded repeated sessions since cookies do not necessarily allow for the possibility of exploiting similarities in click behavior across sessions for each consumer, owing to the usage of one device by multiple consumers or usage of multiple devices by one consumer (Chatterjee et al. 2003). Finally, while our data set provided insights across three online 
channels, future research might generate further insights by analyzing additional online channels, such as third-party websites. Moreover, analyzing the resulting profit effects across different channels could provide rich insights for companies and would be an interesting extension to our study.

\section{Conclusion}

This study shows that the online channel through which a consumer reaches a VOD website is important for understanding their behavior on the website. By focusing on consumers of one particular VOD website, this study finds that the way in which consumers reach a website is related to their stickiness to the website (e.g., visit length, number of page views, video starts) and their propensity to refer videos to others via sharing buttons. The results show that consumers referred through social referrals spend more time on the website, view more pages, and start more videos than consumers who respond to social media advertisements, but less than those coming through organic search. Furthermore, consumers already attracted through social referrals are more likely to refer content to others than those who have come through organic search or social media advertisements.

Acknowledgement Open Access funding provided by Projekt DEAL.

Open Access This article is licensed under a Creative Commons Attribution 4.0 International License, which permits use, sharing, adaptation, distribution and reproduction in any medium or format, as long as you give appropriate credit to the original author(s) and the source, provide a link to the Creative Commons licence, and indicate if changes were made. The images or other third party material in this article are included in the article's Creative Commons licence, unless indicated otherwise in a credit line to the material. If material is not included in the article's Creative Commons licence and your intended use is not permitted by statutory regulation or exceeds the permitted use, you will need to obtain permission directly from the copyright holder. To view a copy of this licence, visit http://creativecommons. org/licenses/by/4.0/.

\section{References}

Alpar P, Porembski M, Pickerodt S (2001) Measuring the efficiency of web site traffic generation. Int J Electron Commer 6(1):53-74. https://doi.org/10.1080/10864415.2001.11044224

Anderl E, Schumann JH, Kunz W (2016) Helping firms reduce complexity in multichannel online data: a new taxonomy-based approach for customer journeys. J Retail 92(2):185-203. https:// doi.org/10.1016/j.jretai.2015.10.001

Bar-Gill S, Inbar Y, Reichman S (2018) The impact of social vs. nonsocial referring channels on online news consumption. http://dx. doi.org/10.2139/ssrn.3119943
Ben-Akiva ME, Lerman SR (1985) Discrete choice analysis: theory and application to travel demand. MIT Press, Cambridge

Benlian A (2015) Web personalization cues and their differential effects on user assessments of website value. J Manag Inf Syst 32(1):225-260. https://doi.org/10.1080/07421222.2015.1029394

Berger J (2014) Word of mouth and interpersonal communication: a review and directions for future research. J Consum Psychol 24(4):586-607. https://doi.org/10.1016/j.jcps.2014.05.002

Berger J, Schwartz EM (2011) What drives immediate and ongoing word of mouth? J Mark Res 48(5):869-880. https://doi.org/10. 1509/jmkr.48.5.869

Bhatnagar A, Ghose S (2004) An analysis of frequency and duration of search on the internet. J Bus 77(2):311-330. https://doi.org/ $10.1086 / 381277$

Bhatnagar A, Sen A, Sinha AP (2016) Research note - providing a window of opportunity for converting estore visitors. Inf Syst Res 28(1):22-32. https://doi.org/10.1287/isre.2016.0655

Biyalogorsky E, Gerstner E, Libai B (2001) Customer referral management: optimal reward programs. Mark Sci 20(1):82-95

Borgatti SP, Everett MG (1992) Notions of position in social network analysis. Sociol Methodol 22(1):1-35. https://doi.org/10.2307/ 270991

Braun M, Moe WW (2013) Online display advertising: modeling the effects of multiple creatives and individual impression histories. Mark Sci 32(5):753-767. https://doi.org/10.1287/mksc.2013. 0802

Bucklin RE, Sismeiro C (2009) Click here for internet insight: advances in clickstream data analysis in marketing. $\mathrm{J}$ Interact Mark 23(1):35-48. https://doi.org/10.1016/j.intmar.2008.10.004

Burtch G, Ghose A, Wattal S (2014) An empirical examination of peer referrals in online crowdfunding. In: Proceedings of the 35th international conference on information systems, Auckland

Castilla EJ (2005) Social networks and employee performance in a call center. Am J Sociol 110(5):1243-1283. https://doi.org/10. $1086 / 427319$

Chan TY, Wu C, Xie Y (2011) Measuring the lifetime value of customers acquired from google search advertising. Mark Sci 30(5):837-850. https://doi.org/10.1287/mksc.1110.0658

Chatterjee P, Hoffman DL, Novak TP (2003) Modeling the clickstream: implications for web-based advertising efforts. Mark Sci 22(4):520-541. https://doi.org/10.1287/mksc.22.4. 520.24906

Chen Z, Berger J (2016) How content acquisition affects word of mouth. J Consum Res 43(1):86-102. https://doi.org/10.1093/jcr/ ucw001

Chen Y, Xie J (2007) Online consumer review: word-of-mouth as a new element of marketing communication mix. Manag Sci 54(3):477-491. https://doi.org/10.1287/mnsc.1070.0810

Chen P-Y, Wu S-Y, Yoon J (2004) The impact of online recommendations and consumer feedback on sales. In: Proceedings of the 25th international conference on information systems, Washington

Cheung CMK, Thadani DR (2012) The impact of electronic word-ofmouth communication: a literature analysis and integrative model. Decis Support Syst 54(1):461-470. https://doi.org/10. 1016/j.dss.2012.06.008

Chevalier JA, Mayzlin D (2006) The effect of word of mouth on sales: online book reviews. J Mark Res 43(3):345-354. https:// doi.org/10.1509/jmkr.43.3.345

Coleman JS (1988) Social capital in the creation of human capital. Am J Sociol 94(1):95-120

Costello P (2015) Social share buttons analysis. http://blog.naytev. com/social-share-buttons-analysis/. Accessed 1 May 2020

Cyr D, Head M, Larios H, Pan B (2009) Exploring human images in website design: a multi-method approach. MIS Q 33(3):539-566. https://doi.org/10.2307/20650308 
Danaher PJ, Mullarkey GW, Essegaier S (2006) Factors affecting web site visit duration: a cross-domain analysis. J Mark Res 43(2):182-194. https://doi.org/10.1509/jmkr.43.2.182

De Bruyn A, Lilien GL (2008) A multi-stage model of word-of-mouth influence through viral marketing. Int $\mathrm{J}$ Res Mark 25(3):151-163. https://doi.org/10.1016/j.ijresmar.2008.03.004

De Keyzer F, Dens N, De Pelsmacker P (2015) Is this for me? How consumers respond to personalized advertising on social network sites. J Interact Advert 15(2):124-134. https://doi.org/10.1080/ 15252019.2015.1082450

De Matos CA, Rossi CAV (2008) Word-of-mouth communications in marketing: a meta-analytic review of the antecedents and moderators. J Acad Mark Sci 36(4):578-596. https://doi.org/10. 1007/s11747-008-0121-1

Demers E, Lev B (2001) A rude awakening: internet shakeout in 2000. Rev Account Stud 6(2):331-359. https://doi.org/10.1023/ A: 1011675227890

Dichter E (1966) How word-of-mouth advertising works. Harvard Bus Rev 44(6):147-160

Garnefeld I, Eggert A, Helm SV, Tax SS (2013) Growing existing customers' revenue streams through customer referral programs. J Mark 77(4):17-32. https://doi.org/10.1509/jm.11.0423

Ghandour A, Benwell G, Deans K (2010) Measuring the performance of ecommerce websites. In: Proceedings of the 14th Pacific Asia conference on information systems, Taipei

Ghose A, Todri-Adamopoulos V (2016) Toward a digital attribution model: measuring the impact of display advertising on online consumer behavior. MIS Q 40(4):889-910. https://doi.org/10. 25300/MISQ/2016/40.4.05

Ghose A, Yang S (2009) An empirical analysis of search engine advertising: sponsored search in electronic markets. Manag Sci 55(10):1605-1622. https://doi.org/10.1287/mnsc.1090.1054

Ghose A, Goldfarb A, Han SP (2012) How is the mobile internet different? Search costs and local activities. Inf Syst Res 24(3):613-631. https://doi.org/10.1287/isre.1120.0453

Godes D, Mayzlin D (2004) Using online conversations to study word-of-mouth communication. Mark Sci 23(4):545-560. https://doi.org/10.1287/mksc.1040.0071

Goh K-Y, Heng C-S, Lin Z (2013) Social media brand community and consumer behavior: quantifying the relative impact of userand marketer-generated content. Inf Syst Res 24(1):88-107. https://doi.org/10.1287/isre.1120.0469

Greene WH (2003) Econometric analysis. Prentice Hall, Upper Saddle River

Gu B, Park J, Konana P (2012) Research note: the impact of external word-of-mouth sources on retailer sales of high-involvement products. Inf Syst Res 23(1):182-196. https://doi.org/10.1287/ isre. 1100.0343

Heath C, Bell C, Sternberg E (2001) Emotional selection in memes: the case of urban legends. J Pers Soc Psychol 81(6):1028-1041. https://doi.org/10.1037/0022-3514.81.6.1028

Heimbach I, Kostyra DS, Hinz O (2015) Marketing automation. Bus Inf Syst Eng 57(2):129-133. https://doi.org/10.1007/s12599015-0370-8

Hemmert GAJ, Schons LM, Wieseke J, Schimmelpfennig H (2018) Log-likelihood-based pseudo-R2 in logistic regression: deriving sample-sensitive benchmarks. Sociol Method Res 47(3):507-531. https://doi.org/10.1177/0049124116638107

Hennig-Thurau T, Gwinner KP, Walsh G, Gremler DD (2004) Electronic word-of-mouth via consumer-opinion platforms: what motivates consumers to articulate themselves on the internet? J Interact Mark 18(1):38-52. https://doi.org/10.1002/dir.10073

Hosmer DW, Lemeshow S, Sturdivant RX (2013) Applied logistic regression, vol 398. Wiley, Hoboken

Huang P, Lurie NH, Mitra S (2009) Searching for experience on the web: an empirical examination of consumer behavior for search and experience goods. J Mark 73(2):55-69. https://doi.org/10. 1509/jmkg.73.2.55

Kannan PK, Reinartz W, Verhoef PC (2016) The path to purchase and attribution modeling: introduction to special section. Int J Res Mark 33(3):449-456. https://doi.org/10.1016/j.ijresmar.2016.07. 001

King G, Zeng L (2001) Logistic regression in rare events data. Polit Anal 9(2):137-163. https://doi.org/10.1093/oxfordjournals.pan. a004868

Koch OF, Benlian A (2015) Designing viral promotional campaigns: how scarcity and social proof affect online referrals. In: Proceedings of the 36th international conference on information systems, Fort Worth

Köster A, Matt C, Hess T (2015) The role of communication types on referral acceptance in social networks. In: Proceedings of the 21st Americas conference on information systems, Fajardo, Puerto Rico

Kotler P, Armstrong G (2010) Principles of marketing. Prentice Hall, New Jersey

Li X, Hitt LM (2008) Self-selection and information role of online product reviews. Inf Syst Res 19(4):456-474. https://doi.org/10. 1287/isre.1070.0154

Li H, Kannan P (2014) Attributing conversions in a multichannel online marketing environment: an empirical model and a field experiment. J Mark Res 51(1):40-56. https://doi.org/10.1509/ jmr. 13.0050

Lin JC-C (2007) Online stickiness: its antecedents and effect on purchasing intention. Behav Inf Technol 26(6):507-516. https:// doi.org/10.1080/01449290600740843

Lin T-C, Hsu JS-C, Chen H-C (2013) Customer willingness to pay for online music: the role of free mentality. J Electron Commer Res 14(4):315-333

Lis B, Neßler C (2013) Electronic word of mouth. Bus Inf Syst Eng 6(1):63-65. https://doi.org/10.1007/s12599-013-0306-0

Lu X, Ba S, Huang L, Feng Y (2013) Promotional marketing or wordof-mouth? Evidence from online restaurant reviews. Inf Syst Res 24(3):596-612. https://doi.org/10.1287/isre.1120.0454

Lucas W, Schiano W, Crosett K (2001) The present and future of internet search. Commun Assoc for Inf Syst 5(1):1-29. https:// doi.org/10.17705/1CAIS.00508

Luo X, Zhang J, Duan W (2013) Social media and firm equity value. Inf Syst Res 24(1):146-163. https://doi.org/10.1287/isre.1120. 0462

Mahnke R, Benlian A, Hess T (2015) A grounded theory of online shopping flow. Int J Electron Commer 19(3):54-89. https://doi. org/10.1080/10864415.2015.1000222

Manski CF, Lerman SR (1977) The estimation of choice probabilities from choice based samples. Econometrica 45(8):1977-1988

Mao E, Zhang J (2015) What drives consumers to click on social media ads? The roles of content, media, and individual factors. In: Proceedings of the 48th Hawaii international conference on system sciences, Hawaii. https://doi.org/10.1109/HICSS.2015. 410

Marchand A, Hennig-Thurau T, Wiertz C (2016) Not all digital word of mouth is created equal: understanding the respective impact of consumer reviews and microblogs on new product success. Int $\mathrm{J}$ Res Mark 34(2):336-354. https://doi.org/10.1016/j.ijresmar. 2016.09.003

Matook S, Brown SA, Rolf J (2015) Forming an intention to act on recommendations given via online social networks. Eur J Inf Syst 24(1):76-92. https://doi.org/10.1057/ejis.2013.28

Moe WW (2003) Buying, searching, or browsing: differentiating between online shoppers using in-store navigational clickstream. J Consum Psychol 13(1):29-39. https://doi.org/10.1207/ S15327663JCP13-1\&2_03 
Nagelkerke N (1991) A note on a general definition of the coefficient of determination. Biometrika 78(3):691-692. https://doi.org/10. 1093/biomet/78.3.691

Nahapiet J, Ghoshal S (1998) Social capital, intellectual capital, and the organizational advantage. Acad Manag Rev 23(2):242-266. https://doi.org/10.5465/amr.1998.533225

Nelson P (1970) Information and consumer behavior. J Polit Econ 78(2):311-329. https://doi.org/10.1086/259630

Oestreicher-Singer G, Zalmanson L (2013) Content or community? A digital business strategy for content providers in the social age. MIS Q 37(2):591-616. https://doi.org/10.25300/MISQ/2013/37. 2.12

Özpolat K, Gao G, Jank W, Viswanathan S (2013) Research note-the value of third-party assurance seals in online retailing: an empirical investigation. Inf Syst Res 24(4):1100-1111. https:// doi.org/10.1287/isre.2013.0489

Phelps JE, Lewis R, Mobilio L, Perry D, Raman N (2004) Viral marketing or electronic word-of-mouth advertising: examining consumer responses and motivations to pass along email. J Advert Res 44(4):333-348. https://doi.org/10.1017/ S0021849904040371

Pihlström M, Brush GJ (2008) Comparing the perceived value of information and entertainment mobile services. Psychol Mark 25(8):732-755. https://doi.org/10.1002/mar.20236

Porter L, Golan GJ (2006) From subservient chickens to brawny men. J Interact Advert 6(2):4-33. https://doi.org/10.1080/15252019. 2006.10722116

Probst F, Grosswiele L, Pfleger R (2013) Who will lead and who will follow: identifying influential users in online social networks. Bus Inf Syst Eng 5(3):179-193. https://doi.org/10.1007/s12599013-0263-7

Rishika R, Kumar A, Janakiraman R, Bezawada R (2013) The effect of customers' social media participation on customer visit frequency and profitability: an empirical investigation. Inf Syst Res 24(1):108-127. https://doi.org/10.1287/isre.1120.0460

Rogers EM (2003) Diffusion of innovations. The Free Press, New York

Ryu G, Feick L (2007) A penny for your thoughts: referral reward programs and referral likelihood. J Mark 71(1):84-94. https:// doi.org/10.1509/jmkg.71.1.084

Schmitt P, Skiera B, Van den Bulte C (2011) Referral programs and customer value. J Mark 75(1):46-59. https://doi.org/10.2307/ 25764294

Schwarzer M, Schubotz M, Meuschke N, Breitinger C, Markl V, Gipp B (2016) Evaluating link-based recommendations for Wikipedia. In: Proceedings of the 16th ACM/IEEE-CS on joint conference on digital libraries. https://doi.org/10.1145/2910896.2910908

Senecal S, Nantel J (2004) The influence of online product recommendations on consumers' online choices. J Retail 80(2):159-169. https://doi.org/10.1016/j.jretai.2004.04.001

Shi N, Hong Y, Wang K, Pavlou P (2013) Social commerce beyond word of mouth: role of social distance and social norms in online referral incentive systems. In: Proceedings of the 34th international conference on information systems, Milan
Spann M, Hinz O, Ramachandran V (2013) Business and information systems engineering and marketing. Bus Inf Syst Eng 5(3):127-128. https://doi.org/10.1007/s12599-013-0264-6

Trueman B, Wong MHF, Zhang X-J (2000) The eyeballs have it: searching for the value in internet stocks. J Account Res 38(1):137-162. https://doi.org/10.2307/2672912

Trusov M, Bucklin RE, Pauwels K (2009) Effects of word-of-mouth versus traditional marketing: findings from an internet social networking site. J Mark 73(5):90-102. https://doi.org/10.1509/ jmkg.73.5.90

Vakratsas D, Ambler T (1999) How advertising works: what do we really know? J Mark 63(1):26-43. https://doi.org/10.2307/ 1251999

Van den Bulte C, Lilien GL (2001) Two-stage partial observability models of innovation adoption. University of Pennsylvania, pp $1-47$

van Herpen E, Pieters R, Zeelenberg M (2009) When demand accelerates demand: trailing the bandwagon. J Consum Psychol 19(3):302-312. https://doi.org/10.1016/j.jcps.2009.01.001

Verhoef PC, Venkatesan R, McAlister L, Malthouse EC, Krafft M, Ganesan S (2010) CRM in data-rich multichannel retailing environments: a review and future research directions. J Interact Mark 24(2):121-137. https://doi.org/10.1016/j.intmar.2010.02. 009

Verlegh PW, Ryu G, Tuk MA, Feick L (2013) Receiver responses to rewarded referrals: the motive inferences framework. J Acad Mark Sci 41(6):669-682. https://doi.org/10.1007/s11747-0130327-8

Villanueva J, Yoo S, Hanssens DM (2008) The impact of marketinginduced versus word-of-mouth customer acquisition on customer equity growth. J Mark Res 45(1):48-59. https://doi.org/10.1509/ jmkr.45.1.48

Wiesel T, Pauwels K, Arts J (2011) Marketing's profit impact: quantifying online and off-line funnel progression. Mark Sci 30(4):604-611. https://doi.org/10.1287/mksc.1100.0612

Wong D (2014) In Q4, social media drove $31.24 \%$ of overall traffic to sites [report]. Shareaholic Reports. https://blog.shareaholic.com/ social-media-traffic-trends-01-2015/. Accessed 16 Jan 2016

Wooldridge J (2015) Introductory econometrics: a modern approach. South-Western

Xu L, Duan JA, Whinston A (2014) Path to purchase: a mutually exciting point process model for online advertising and conversion. Manag Sci 60(6):1392-1412. https://doi.org/10.1287/mnsc. 2014.1952

Yang S, Ghose A (2010) Analyzing the relationship between organic and sponsored search advertising: positive, negative, or zero interdependence? Mark Sci 29(4):602-623. https://doi.org/10. 1287/mksc. 1100.0552

Zhang P (2011) What consumers think, feel, and do toward digital ads: a multi-phase study. In: Proceedings of the 19th European conference on information systems, Helsinki

Zhang Y, Feick L, Mittal V (2014) How males and females differ in their likelihood of transmitting negative word of mouth. J Consum Res 40(6):1097-1108. https://doi.org/10.1086/674211 